\title{
Uma novela de Rosa: um auto de Suassuna e um encontro entre $o$ erudito, o popular e o massivo que o cinema e a televisão possibilitam
}

Maria Ignês Carlos Magno

Doutora em Ciências da Comunicação pela ECA/USP. Professora do mestrado em Comunicação da Universidade Anhembi Morumbi e da Fundação Escola de Sociologia e Política de São Paulo.

E-mail: unsigster@gmail.com

Resumo: Nesta seção de Videografia a proposta é realizar um estudo conjunto de duas produções audiovisuais, dada a constatação de que algumas destas, quando adaptadas para o cinema ou para a televisão, têm a aceitação de todos os tipos de público, independentemente de regiões ou classes sociais, incluindo professores e alunos. Nesta perspectiva, foi escolhido o filme Mutum (2007), de Sandra Kogut, inspirado na história de Miguilim, da novela Campo Geral, de João Guimarães Rosa (1956), e a minissérie Auto da Compadecida (1999), de Guel Arraes, concebida a partir do texto teatral de Ariano Suassuna (1955).

Palavras-chave: cinema, televisão, erudito, massivo, popular.
Abstract: In this section of Videography, we propose a study on two audiovisual productions. We have verified that some literary works, when adapted to cinema or television, are accepted by all kinds of audience, including teachers and students, regardless the region or social class they are from. It was in this perspective, that we chose the motion pictures Mutum (2007), by Sandra Kogut, inspired by Miguilim, from the novel Campo Geral by João Guimarães Rosa (1956), and the miniseries Auto da Compadecida (1999), by Guel Arraes, conceived from the theater play by Ariano Suassuna (1955).

Keywords: cinema, television, erudite, massive, popular. 
comunicação \& educação • Ano XV • número 3 • set/dez 2010

\begin{abstract}
Para fazer poesia - "uma armação de objetos lúdicos com emprego de palavras, imagens, cores, sons etc., geralmente feitos por crianças, pessoas esquisitas, loucos e bêbados" convém primeiro passar os olhos pelo cinema, sugere Manoel de Barros [...]. Para fazer cinema - "um cinema ligado ao povo, que libere o povo brasileiro no sentido de apurar o seu comportamento não dependente de um modelo prescrito por uma sociedade" - convém primeiro passar os olhos pela literatura, sugere Nelson Pereira dos Santos ${ }^{1}$.
\end{abstract}

Um dos debates que sempre vêm à tona nas salas de aula e entre os professores é o de que os meios de comunicação massivos, incluindo nesse grupo o computador, trazem em si as marcas da alienação e do empobrecimento da cultura. Pensando nessa e em outras questões que permeiam o universo escolar, observando a produção televisual e cinematográfica no Brasil e acompanhando as discussões sobre cultura e produção cultural nas últimas décadas, consideramos interessante para esta videografia, além da indicação de filmes e possíveis pesquisas que esses demandam e favorecem, propor um estudo conjunto de produções realizadas para o cinema e a televisão.

Apesar de o cinema hoje conseguir ser visto como fonte digna de pesquisa nas salas de aula, isso ainda não acontece com igual intensidade na televisão em seus diferentes níveis e formatos, mesmo quando as produções são consideradas excelentes em seus conteúdos e reconhecidas em suas qualidades visuais. Embora o foco da seção seja sugerir filmes e apresentar algumas possibilidades de leituras e pesquisas a partir deles, a proposta de um trabalho conjunto de pesquisa e leitura de produções realizadas para o cinema e a televisão nasceu da constatação de que algumas delas, cujas origens estejam na literatura ou no teatro, por exemplo, quando adaptadas têm aceitação de todos os tipos de público, independentemente de regiões ou classes sociais, incluindo professores e alunos ${ }^{2}$. Nesta perspectiva, foi escolhido o filme Mutum (2007), de Sandra Kogut, inspirado na história de Miguilim, da novela Campo Geral de João Guimarães Rosa (1956), e a minissérie O Auto da Compadecida (1999), de Guel Arraes, concebida a partir do texto teatral de Ariano Suassuna (1955). Tanto Guimarães Rosa como Suassuna nos dão a pensar a cultura e as cartografias do Brasil, além de serem autores de leituras e estudos obrigatórios para o ingresso nas universidades brasileiras, sejam quais forem os cursos.

No release de divulgação do filme é informado que Mutum quer dizer mudo; é uma ave negra que só canta à noite, e também um lugar isolado no sertão de Minas Gerais, onde o filme foi rodado. A região tem poucas estradas, é isolada e ainda sem energia elétrica. É nela que vivem Thiago e sua família. Mutum foi inspirado na história de Miguilim, da novela Campo Geral (Manuelzão e Miguilim), de João Guimarães Rosa (1908-1967), considerado o maior escritor brasileiro do século XX, autor de obras-primas como Sagarana e Grande Sertão: Veredas. Miguilim é a história preferida de Guimarães, porque nela dizia achar tudo que havia escrito e tudo que viria a escrever, porque nessa história estava o germe de tudo. 


\section{Uma novela de Rosa - Maria Ignês Carlos Magno}

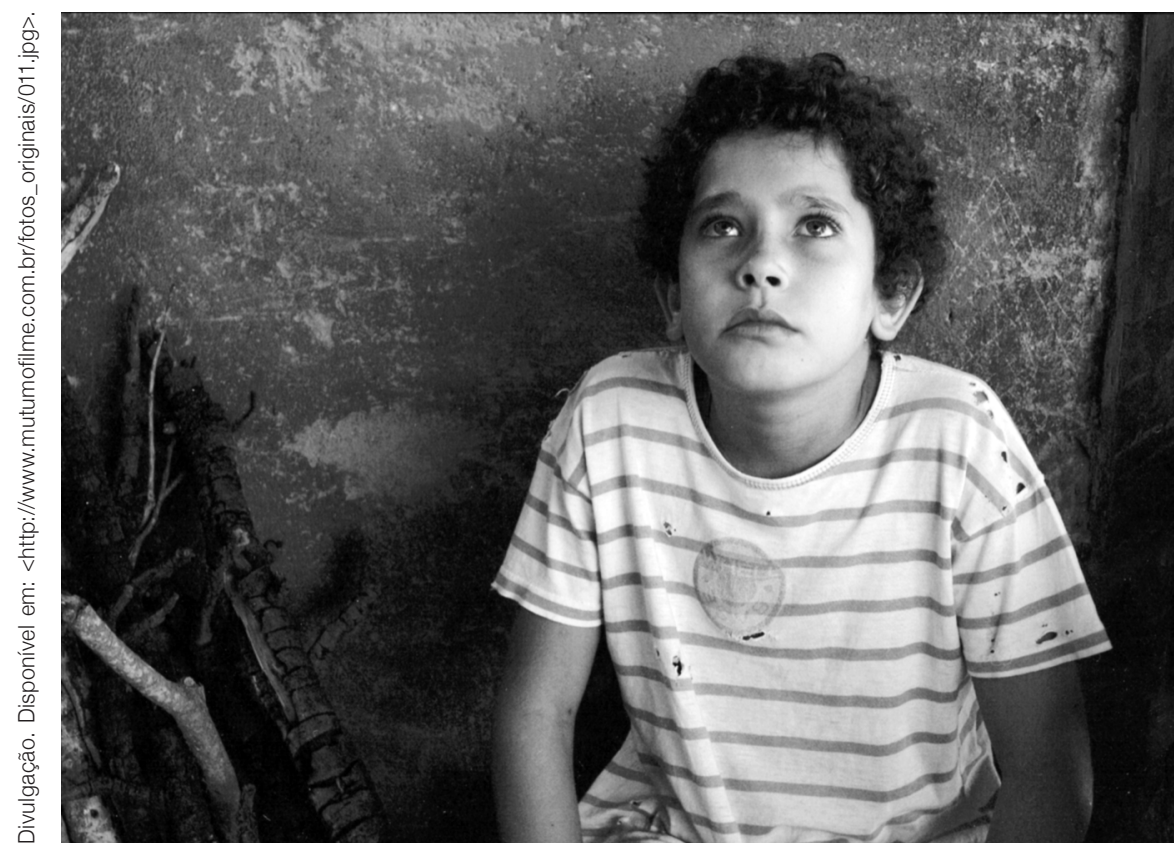

Mutum. O garoto Thiago da Silva Mariz, protagonista do filme, nunca tinha ido ao cinema até ver a própria atuação em uma sessão.

A minissérie $O$ Auto da Compadecida, por sua vez, transcorre no sertão da Paraíba, no vilarejo de Taperoá, que em tupi significa habitante das taperas ou ruínas. É também a cidade natal de Ariano Suassuna. A versão para o cinema foi filmada em Cabeceiras, região próxima de Taperoá, lugarejo onde a história de João Grilo e Chicó acontece. Como diz a sinopse: dois nordestinos sem eira nem beira andam pela rua anunciando A Paixão de Cristo, "o filme mais arretado do mundo".

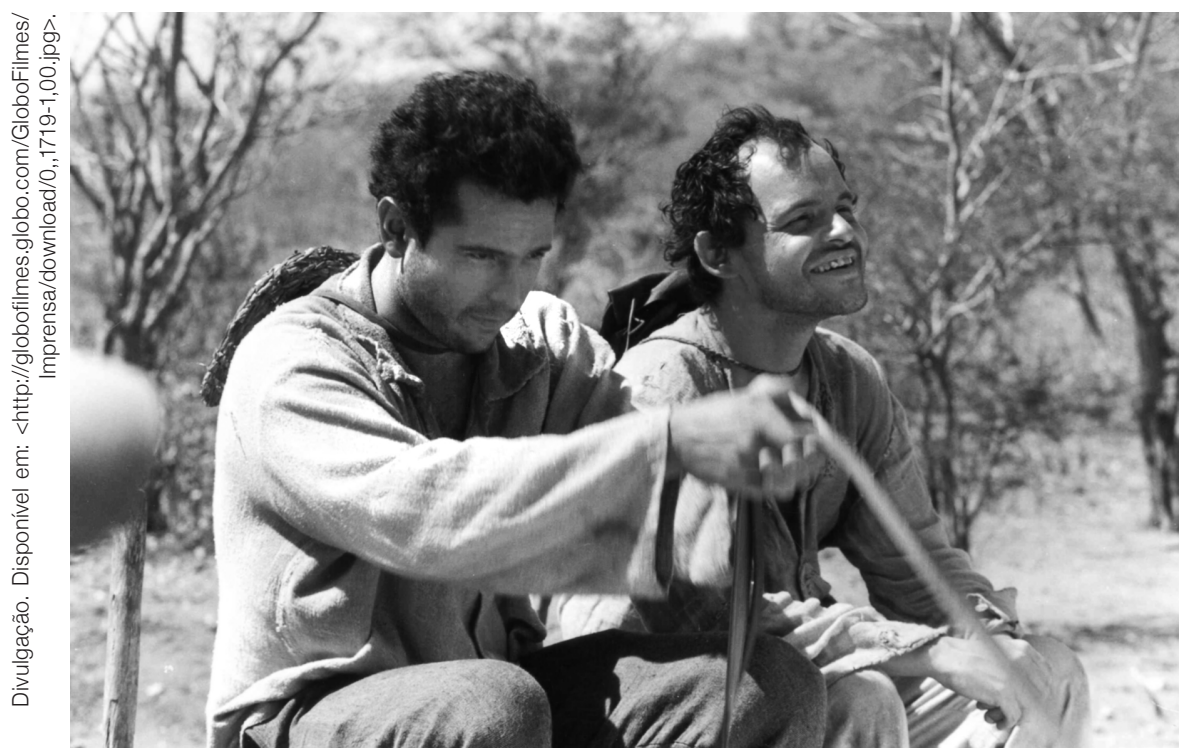

O Auto da Compadecida. Os amigos aventureiros Chicó (Selton Mello) e João Grilo (Matheus Nachtergaele), no auto de Suassuna: estrutura do teatro medieval português e a tradição oral dos romanceiros e narrativas nordestinas. 
comunicação \& educação • Ano XV • número 3 • set/dez 2010

Comecemos então pelo Auto/peça teatral, um dos maiores sucessos do teatro, da televisão e do cinema brasileiros. A minissérie foi levada ao ar pela TV Globo entre os dias 05/01/1999 a 08/01/1999.

\section{FICHA TÉCNICA}

Título original - O Auto da Compadecida

Direção: Guel Arraes e João Falcão

Roteiro: Guel Arraes, Adriana Falcão e João Falcão

Diretor de fotografia: Felix Momti

Direção de arte: Lia Renha

Montagem: Paulo Henrique Farias

Figurino: Cao Albuquerque

Música: Sa Grama

Ano: 1999

De acordo com a sinopse, a sessão de cinema em Taperoá anunciada pela dupla João Grilo e Chicó foi um sucesso. Os dois ganham alguns trocados, mas a luta pela sobrevivência continua. Eles preparam inúmeros planos para conseguir um pouco de dinheiro. Novos desafios vão surgindo, provocando mais confusões armadas pela esperteza de João Grilo, sempre em parceria com Chicó. Entretanto, a chegada da bela Rosinha, filha de Antonio Morais, desperta a paixão de Chicó, e o ciúme do cabo Setenta. Os planos da dupla, que envolvem o casamento entre Chicó e Rosinha e a posse de uma porca de barro recheada de dinheiro, são interrompidos pela chegada do cangaceiro Severino,

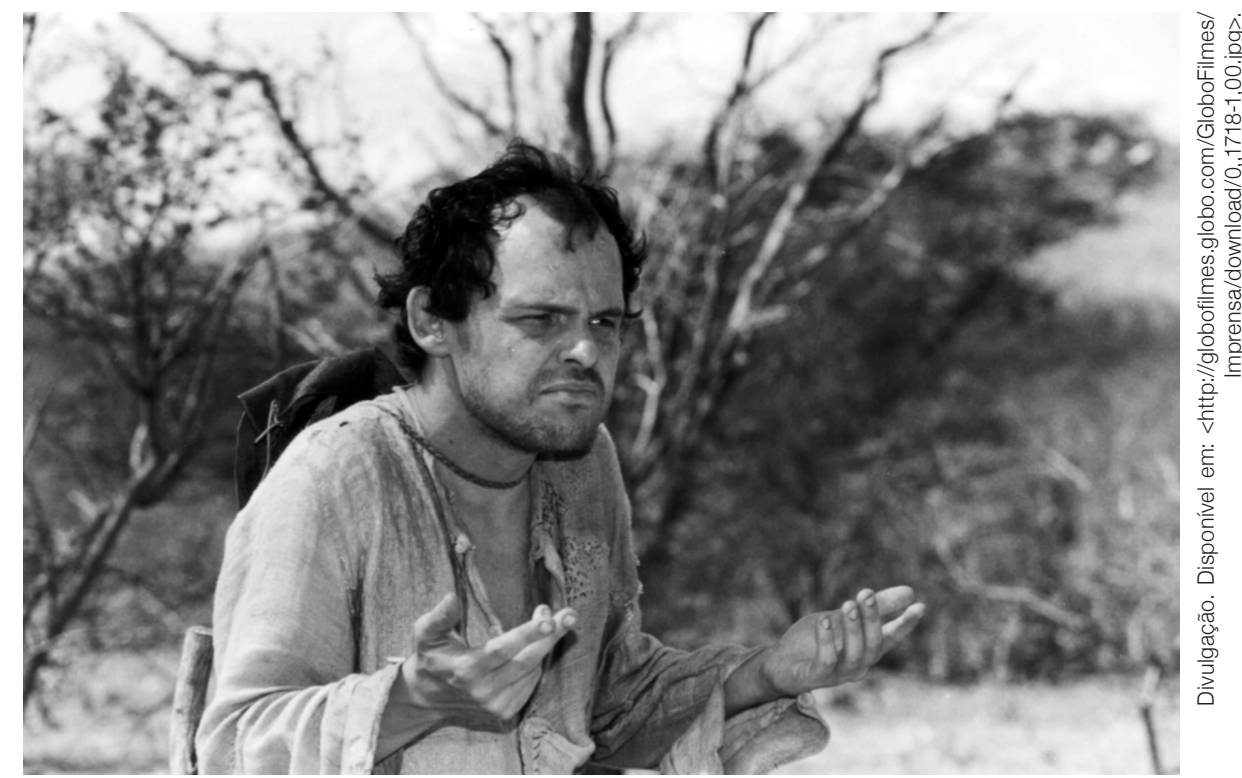

O Auto da Compadecida. João Grilo, figura típica do nordestino sabido, analfabeto e amarelo, é protagonista das situações que conduzem o Auto: bênção e testamento para uma cachorra, uma gaita que "fecha" o corpo e ressuscita, e intervenção e graça da Compadecida. 
que promove uma verdadeira arruaça na cidade e a morte de alguns moradores, inclusive a de João Grilo. Todos os mortos reencontram-se no Juízo Final, onde serão julgados no Tribunal das Almas por um Jesus negro e pelo diabo. O destino de cada um deles será decidido pela aparição de Nossa Senhora, a Compadecida, e traz um final surpreendente, principalmente para João Grilo.

É claro que, se observarmos a data (1999), o meio (TV) e o formato (minissérie) aqui trazidos, pelo menos duas perguntas surgem: por que a televisão e uma minissérie? Por que uma obra levada ao ar dez anos atrás? Como a segunda pergunta já foi em parte justificada na introdução, vamos responder a segunda questão, antes de retomarmos a peça teatral e a produção audiovisual.

Telenovelas, minisséries, seriados televisivos estão sempre na pauta do dia. Mesmo quando não assistimos à TV ou não vemos nenhum desses programas, sabemos o que está acontecendo porque estão disponíveis em todos os lugares por onde passamos: nas bancas de revistas, nas estantes expostas próximo às filas de supermercados, nos jornais diários, nos programas de rádio, nas páginas da internet, entre outras fontes e mídias. Como esses programas já fazem parte de nossa cultura e estão presentes nas conversas em salas de aula e na sala dos professores também, por que não aproveitar e trazer para a escola ou incorporá-los aos conteúdos programáticos? Apesar de ainda termos uma estrutura curricular tradicional, que fundamenta e favorece algumas áreas do conhecimento, disciplinas e profissões, do mesmo modo é verdadeiro o fato de que cada vez mais nossos alunos buscam novos campos e profissões alternativas. Alternativas não porque são diferentes simplesmente, mas porque já fazem parte de um cotidiano e uma realidade que correm paralelos à escola. Os alunos procuram a fotografia, o design gráfico, de interiores, de games, a moda, a gastronomia, o cinema, o rádio, a televisão, a publicidade, apenas para citar algumas delas como possíveis profissões ou objetos de estudos futuros. É verdade, outrossim, que para ingressarem nessas áreas necessitam daquelas disciplinas que fundamentam os currículos e o conhecimento geral. Se tudo isso é real e se não temos uma proposta totalmente alternativa de escola, uma das formas de propiciar esses outros conhecimentos e estudos pode ser os projetos interdisciplinares. Então, por que não termos como foco de pesquisa um dos meios de comunicação massivos mais criticados: a televisão e seus programas? Por que não a minissérie? Por que não histórias e paisagens ficcionadas e atravessadas pelas mais diferentes mídias: o livro, o cinema, a televisão? Meios de comunicação que também possuem história, estética e formatos próprios. Nesses encontros e interferências, são reveladas as possibilidades de um estudo e compreensão das histórias, das geografias, das diferentes linguagens, da televisão e do formato minissérie.

Tanto a telenovela como a minissérie são originárias dos Folhetins. Semelhante à telenovela, a minissérie se diferencia pela duração de seus capítulos, por ter episódios previamente estipulados e seguir sempre um enredo. A primeira minissérie brasileira foi Lampião e Maria Bonita. Escrita por Agnaldo Silva e Doc Comparato, foi exibida pela Rede Globo em 1982 e contava com oito 
3. FAGUNDES, Carla. Auto da Compadecida. Disponível em: <http:// www.vestibulandoweb. com.br/analise_obra/ Auto-da-Compadecida. pdf>. capítulos. Antes, o que havia eram minisséries dubladas, geralmente as produzidas nos Estados Unidos. A partir de Lampião e Maria Bonita, tornaram-se uma constante na televisão brasileira. Além da Rede Globo, outras emissoras, como a extinta Rede Manchete, produziram algumas minisséries e ainda produzem, caso da TV Cultura. Como os enredos quase sempre se baseiam em fatos ou personagens históricos, elas servem como roteiros introdutórios para os estudos de determinados períodos e acontecimentos da história do Brasil. Muitas delas buscam também na literatura a base de seus enredos. Outras vezes a geografia é a personagem principal para recuperarmos as histórias, os contornos e os sentimentos do povo brasileiro.

O texto teatral Auto da Compadecida foi a forma cultural escolhida para ser roteirizada e encenada para a televisão (1999) e depois filmada para o cinema (2000). Esse pode ser um dos aspectos para estudar a minissérie em questão, ou seja, para entender por que um texto teatral deve ser apreendido diferentemente de um romance, de um conto, de uma novela. Outro aspecto é o da estrutura de um auto como uma modalidade do teatro medieval, em que o assunto é essencialmente religioso, especialmente a estrutura desse Auto de Suassuna, que segue a estrutura do teatro medieval português, principalmente o de Gil Vicente. Segundo Carla Fagundes, Auto da Compadecida apresenta elementos que permitem a identificação de sua participação num determinado estilo de época da evolução cultural brasileira, entre eles: "Como o resultado de uma pesquisa sobre a tradição oral dos romanceiros e narrativas nordestinas, fixados ou não em termos de literatura de cordel"3. Como auto, a peça, no entanto, não se divide em atos e o autor dá ao diretor e ao cenógrafo plena liberdade de definirem o estilo da representação. Vale ressaltar, entre tantos outros aspectos que podem ser estudados, o fato

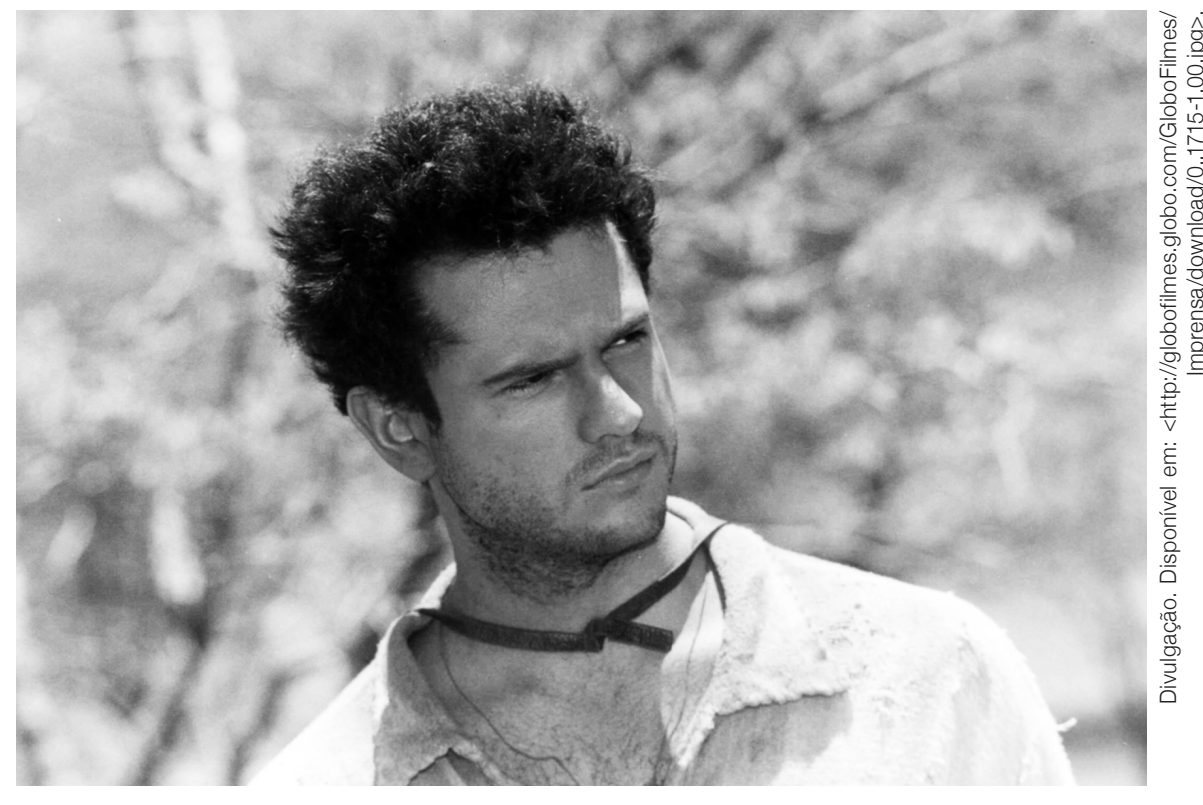

O Auto da Compadecida. Chicó, companheiro constante de João Grilo e dos seus expedientes. É seu parceiro mais por solidariedade do que por convicção. 


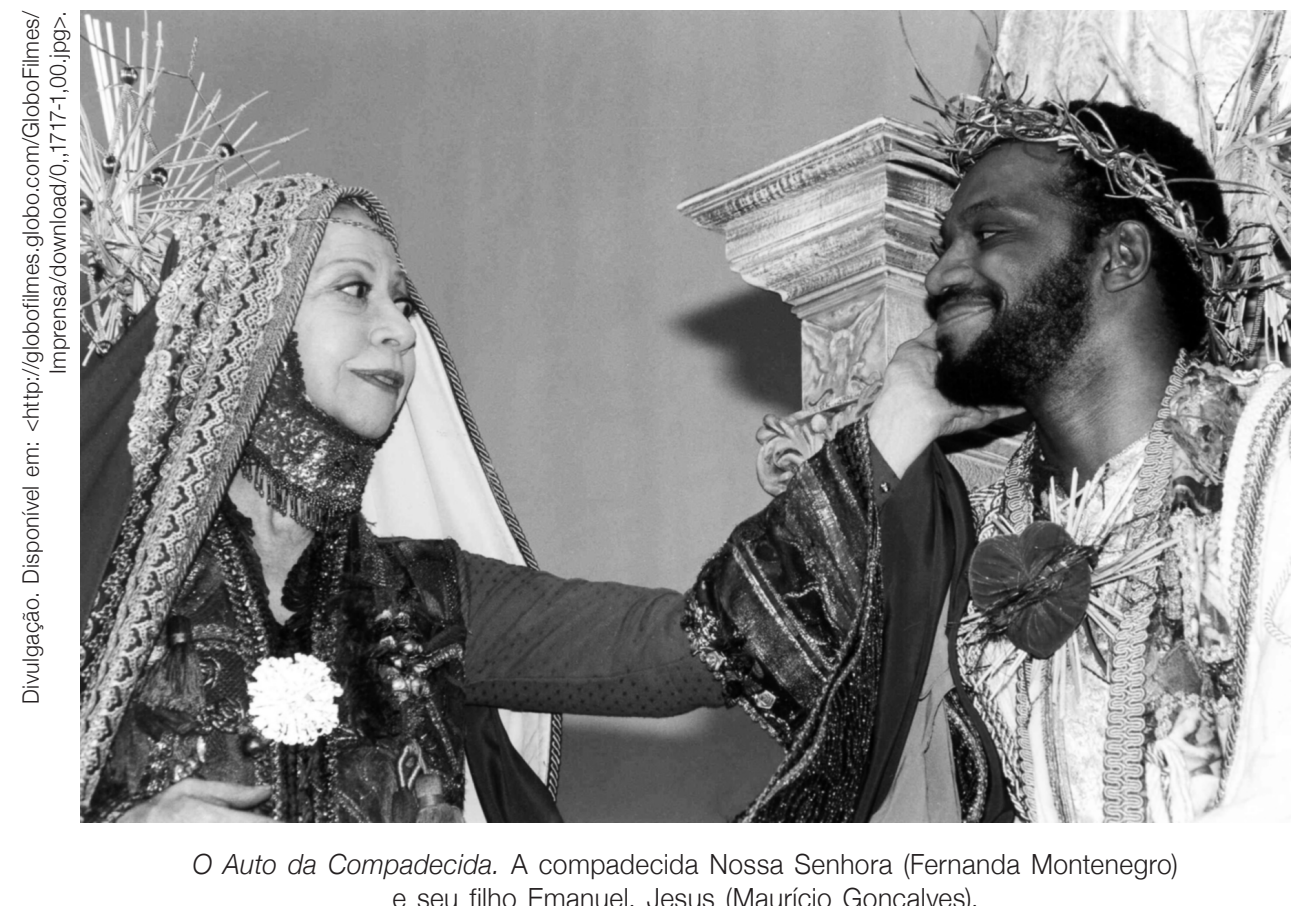

de que Suassuna concebe a peça como uma representação dentro de outra representação. "Claro que seu teatro é o mais aproximado dos espetáculos de circo e da tradição popular do que do teatro moderno", porque "a criação artística, o teatro em particular, devem levar o povo, a cultura desse povo a ele mesmo. Daí o circo, seu picadeiro e a representação dentro da representação" Essa afirmação nos coloca novamente na direção da peça, da estrutura original do Auto da Compadecida como parte de um espetáculo circense, e de sua adaptação para a televisão e cinema.

Embora tenhamos visto que a concepção de um texto teatral difere da concepção de um romance, novela ou conto - e uma das propostas desta videografia é estudar como uma obra teatral ou literária é adaptada para o cinema e para a televisão, no caso uma minissérie -, é fundamental que o professor discuta com os alunos a estrutura da obra, o narrador, o enredo, o tempo, o espaço, as características das personagens, entre outros aspectos da narrativa teatral e literária ${ }^{6}$. Especificamente no caso da minissérie, deve-se observar, por exemplo, a construção das histórias; a trilha sonora e sua relação com o enredo ou personagens; a construção dos diálogos, uma vez que são adaptações de obras e gêneros literários para um tipo de formato que não é o livro, mas vídeo; os movimentos da câmera nos personagens e paisagens, entre outros aspectos visuais, textuais e sonoros. Sem esquecer que se trata de uma adaptação teatral para a televisão, vale um estudo sobre teledramaturgia.

Deixando as espertezas de João Grilo e Chicó em Taperoá, no sertão da Paraíba, vamos nos voltar para Mutum, onde vive Thiago e sua família, personagem do filme do mesmo nome e para onde a câmera de Sandra Kogut nos leva ao sertão de Guimarães Rosa, no meio do Campo Geral.

4. Ibid.

5. Ibid.

6. Sugerimos para estes estudos ANDRADE, Vivian Galdino de. A identidade nordestina: sob o olhar de João Grilo e Chicó. Revista Espaço Acadêmico, ano $\mathrm{VI}, \mathrm{n}$. 69, fev. 2007 (mensal). Disponível em: <http:// www.espacoacademico. com.br/069/69andrade. htm $>$. 
comunicação \& educação • Ano XV • número 3 • set/dez 2010

\section{FICHA TÉCNICA}

Título original: Mutum

Direção: Sandra Kogut

Roteiro: Ana Luiza Martins Costa e Sandra Kogut

Gênero: Drama

Fotografia: Mauro Pinheiro Jr.

Direção de arte: Marcos Pedroso

Edição: Sérgio Mekler

Duração: 95 minutos

Ano: 2007

Site oficial: http://www.mutumofilme.com.br/

A sinopse nos conta que é pelo olhar de Thiago, menino de dez anos e um tanto diferente dos outros, que passamos a enxergar o mundo nebuloso dos adultos, com suas traições, violências e silêncios. Ao lado de seu irmão e único amigo, Thiago será confrontado com este mundo, descobrindo-o ao mesmo tempo em que terá de deixá-lo.

Pelos olhos de Thiago, tão silenciosamente como ele, olhamos o sertão de Guimarães desde os campos, a vida do sertanejo, até "o componente de violência que está na origem de todo poder constituído"7 bem como as relações familiares, os afetos e o próprio silêncio de que é feito o filme. A ausência de música nos obriga a exercitar o que dizia Rosa sobre converter o ouvido em olho e ao mesmo tempo ouvir o que não é dito nos longos silêncios dos olhares de Thiago, do pai, da mãe. Silêncio que feria como arma o pai, que não entendia

7. BOLLE, Willi. Grandesertão.br: o romance de formação do Brasil. São Paulo: Duas Cidades/Ed. 34, 2004. p. 92.

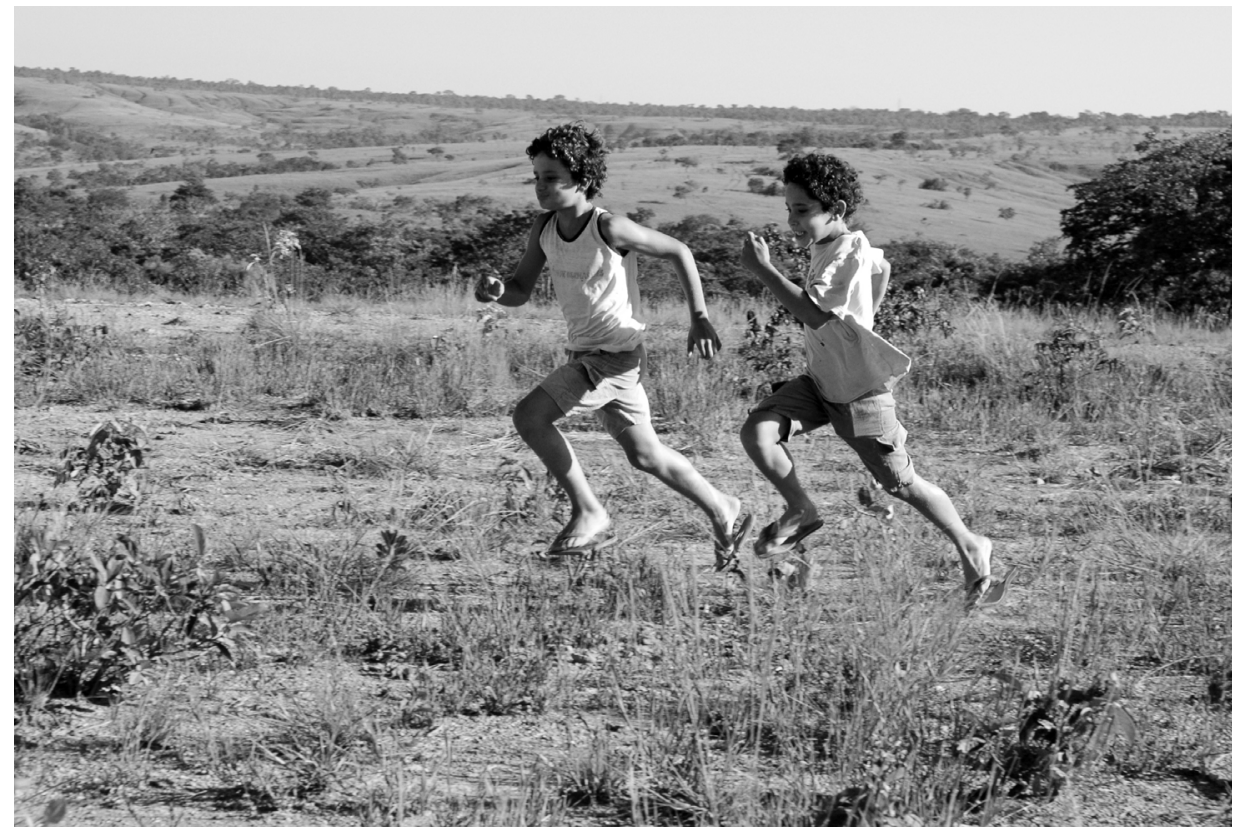

Mutum. A maior parte das pessoas que atua no filme não são atores profissionais. A maioria das crianças e dos vaqueiros nunca foi ao cinema. Tudo foi transmitido oralmente, sem a leitura de um roteiro, e o trabalho de atuação se construiu a partir da proximidade entre a vida deles e a de seus personagens. 


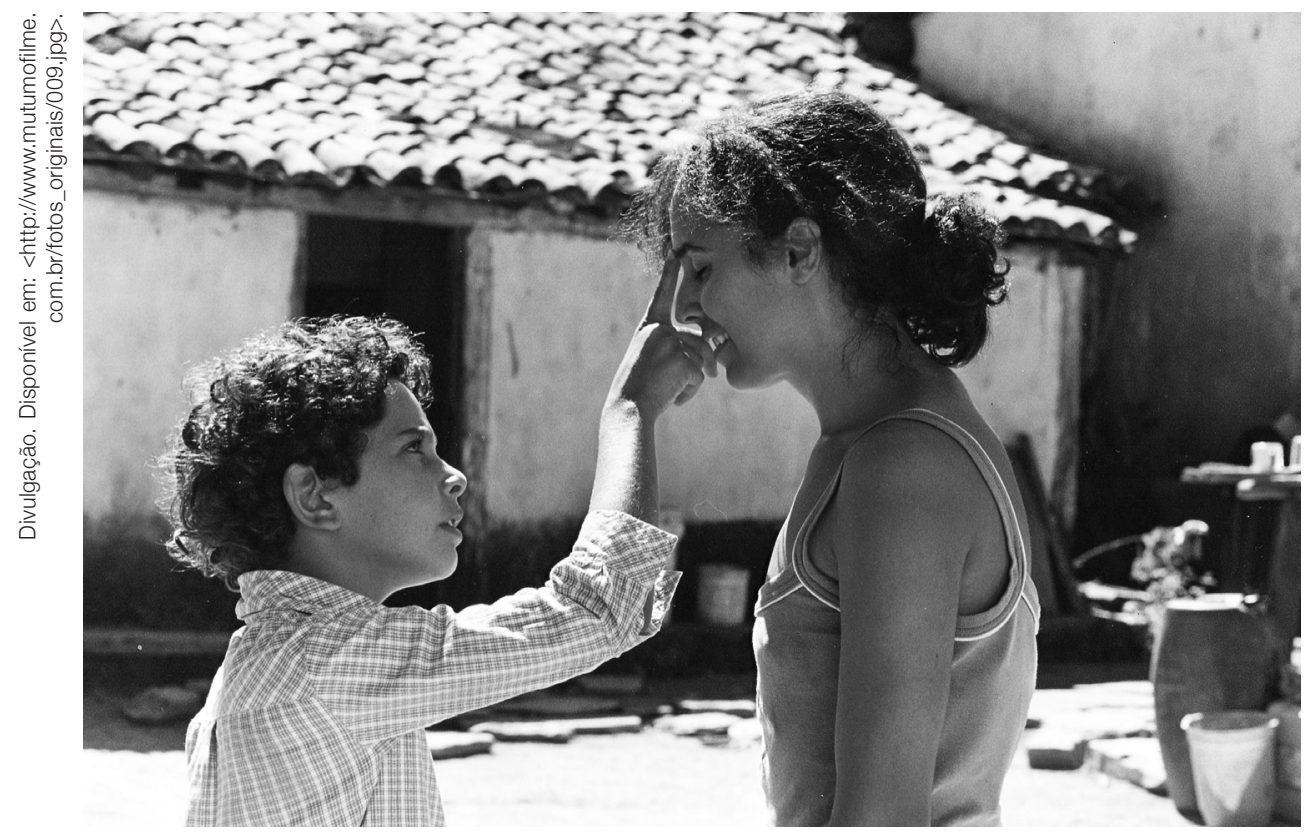

Mutum. No processo de filmagem, os jovens atores - acostumados com a situação de estar numa oficina - juntaram-se aos não atores, que faziam todos os exercícios sem interpretar: eles choravam e riam de verdade, trazendo uma dimensão humana diferente ao trabalho.

os significados dos silêncios do filho. Pelos olhos de Thiago, enxergamos a feitura do filme de Sandra, que, "afastado do puramente verbal de Rosa", fotografou e filmou como Rosa em sua miopia. Em entrevista à revista Veredas, Pedro Bial, ao falar da difícil tarefa que é adaptar Guimarães Rosa, comentou que nas anotações que Rosa fazia em suas cadernetas de campo "fotografava o detalhe, a flor, o olho do cavalo... Ou então, no outro extremo, o grande. Ele não vê o longe, mas o grande, o espaço, o sertão. Era, evidentemente, o olhar de um míope", como Thiago, que ao vestir os óculos enxergou o grande, o espaço, os campos, como eram as pessoas e o rosto da mãe, antes de partir.

Escolhemos Mutum com a intenção de partir do filme para chegar à obra literária e, especialmente, a Guimarães Rosa e sua metodologia, a fim de registrar e escrever o mundo. Glauber Rocha lembra o dia em que o mestre lhe deu cordas, "primeiro, contou que viajara de Montes Claros a Caldas de Cipó pra tomar nota das cores de uns bezerros vermarronzim", e depois "retirou da gaveta uns contos ciganos, à mão, e me pediu para ler em voz alta, advertindo: são contos em cinemascópio colorido"10. Pensamos em Mutum também como avaliação do exercício do fazer cinematográfico de Sandra Kogut e sua metodologia, juntamente com Ana Luiza, para escrever o roteiro e depois filmar. Aproximações interessantes quando lemos o depoimento das autoras durante o ano e meio em que andaram pelo interior de Minas buscando as personagens e lugares para fazer o filme ${ }^{11}$. Exercício que possibilita ao aluno acompanhar o processo de elaboração de um roteiro e do significado de uma escritura em constante fazer(-se) e refazer(-se). Como o cinema, a escritura de Guimarães Rosa estava sempre em movimento. Dizia querer ver o mundo pelos olhos dos vaqueiros, porque nas "culturas boieiras, a natureza não é uma presença estranha, mas ponto de referência para a

8. VASCONCELOS, Mauricio Salles. Pedrez/Paragem /Páramo (Fotogramática). In: FANTINI, Marli (Org.). A poética migrante de Guimarães Rosa. Belo Horizonte: Ed. UFMG, 2008. p. 305.

9. AVELLAR, op. cit., p. 287.

10. Ibid., p. 284.

11. Disponível em: <http: //www.mutumofilme.com. $\mathrm{br} /$ notas.htm $>$. 
comunicação \& educação • Ano XV • número 3 • set/dez 2010

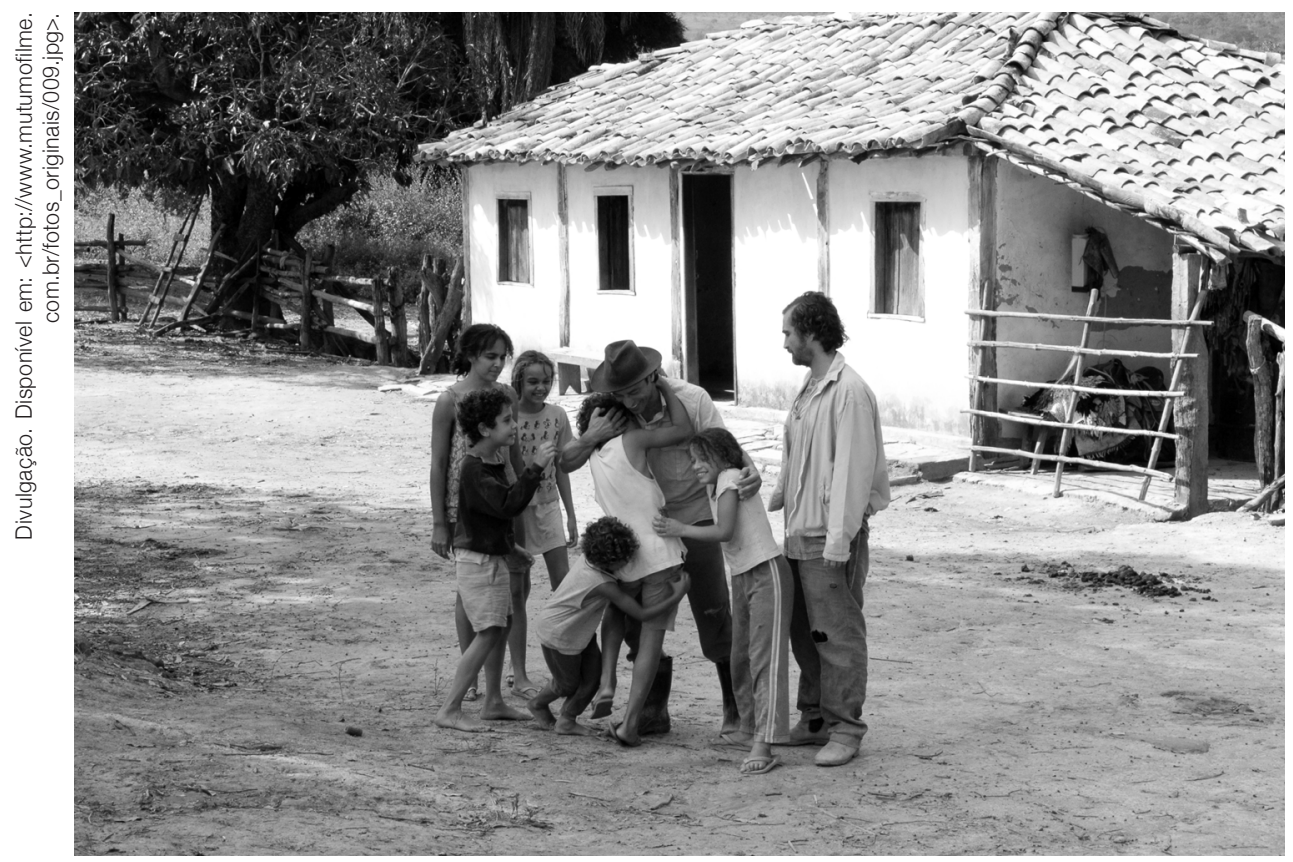

Mutum. A escolha de filmar numa fazenda de verdade não foi por razões etnográficas, mas para permitir que o elenco compartilhasse um cotidiano. Eles trabalhavam juntos, cuidavam dos bichos, capinavam.

vida. Os vaqueiros detêm um profundo conhecimento da natureza, não só do gado, mas de todas as plantas, bichos, rios, montanhas"12. Não por acaso Rosa dizia que sua "literatura era para bois, não era para ser engolida de vez"13. Não por acaso, Sandra e Ana Luiza adentraram no interior das Gerais; não por acaso o filme termina com Thiago indo embora a cavalo em direção ao Campo Geral.

Particularmente interessante é sabermos que Thiago e sua família nunca tinham visto um filme, e desconheciam o cinema e a televisão. A primeira vez que o garoto foi ao cinema, foi para se ver na tela. Passadas as estreias, voltou para o sertão e, quando perguntado se havia contado para os amigos que tinha feito um filme, respondeu: "Pra que, já passou"14.

Ariano Suassuna, jornalista, advogado, escritor. Guimarães Rosa, médico,

12. COSTA, Ana Luiza Martins. João Rosa, viator. In: FANTINI, Marli de Oliveira (Org.). A poética migrante de Guimarães Rosa. Belo Horizonte: Editora UFMG, 2008. p. 328.

13. ROCHA, Glauber. Riverão Sussuarana. Rio de Janeiro: Editora Record, 1978. p. 10-11.

14. KOGUT, Sandra. Crônica de um país bem aberto. Revista O Globo. Rio de Janeiro, p. 34, 18 nov. 2007. Disponível em: $<$ http://www.cinemaemcena.com.br/mutum/ blog.asp>. escritor. Ambos os autores formados na tradição da cultura erudita. Os dois buscaram nas tradições populares suas inspirações, suas pesquisas. Ariano em seu Auto da Compadecida fez a síntese de um modelo de teatro medieval com a tradição oral do romanceiro e das narrativas nordestinas. Rosa, viajante, pesquisa o sertão mineiro, baiano, o Pantanal mato-grossense, coletando as falas, as expressões, os vocábulos, as palavras que compunham o universo do sertanejo, para transformá-las no que há de mais erudito: romances, contos, novelas, com o que há de mais popular, ou seja, a fala do sertanejo, do povo nem sempre letrado, analfabeto em sua maioria, mas possuidor, sempre, de uma cultura singular. Alguns escritores e roteiristas aprenderam a transformar ouvido em olho e transportaram as obras literárias para os meios de comunicação. Esses, por terem como uma de suas características o fato de serem massivos e feitos para serem vistos em larga escala, puderam mostrar e devolver ao povo, em formato de uma minissérie e de um filme, o que antes estava ao alcance de 
poucos. Num dos temas tratados em sua tese de doutorado, Maria Cristina Palma Mungioli teve como objetivo principal compreender um sentido identitário de nação construído pela minissérie Grande Sertão: Veredas, por meio de gêneros e temas. Um dos aspectos estudados em sua pesquisa foi a função social da minissérie na construção de um sentido de nacionalidade por meio de discursos e imagens televisuais que pretendiam mostrar o Brasil aos brasileiros ${ }^{15}$. Por sua vez, essa hibridização cultural, com elementos da cultura erudita e da cultura de massa, revela um processo evidente de circularidade cultural que esfumaça, portanto, os limites entre o erudito e o popular. Para enriquecer essa discussão, recomendamos a leitura do artigo de Walter de Sousa ${ }^{16}$ publicado na revista Comunicação $\mathfrak{E}$ Educação, em que expõe claramente como se dá o processo de circularidade cultural.

15. MUNGIOLI, Maria Cristina Palma. A função social da minissérie Grande Sertão: Veredas na construção de um sentido identitário de nação. Comunicação \& Educação, São Paulo: CCA-ECA-USP/Paulinas, ano XIV, n. 3, set./dez. 2009.

16. SOUSA, Walter de. Piolin e Arrelia: entre o popular, o erudito e o massivo. Comunicação \& Educação, São Paulo: CCA-ECA-USP/Paulinas, ano XIV, n. 3, set./dez. 2009. 


\section{$\mathrm{Na}$ leitura, na escrita, o caminho dos mistérios, das descobertas...}

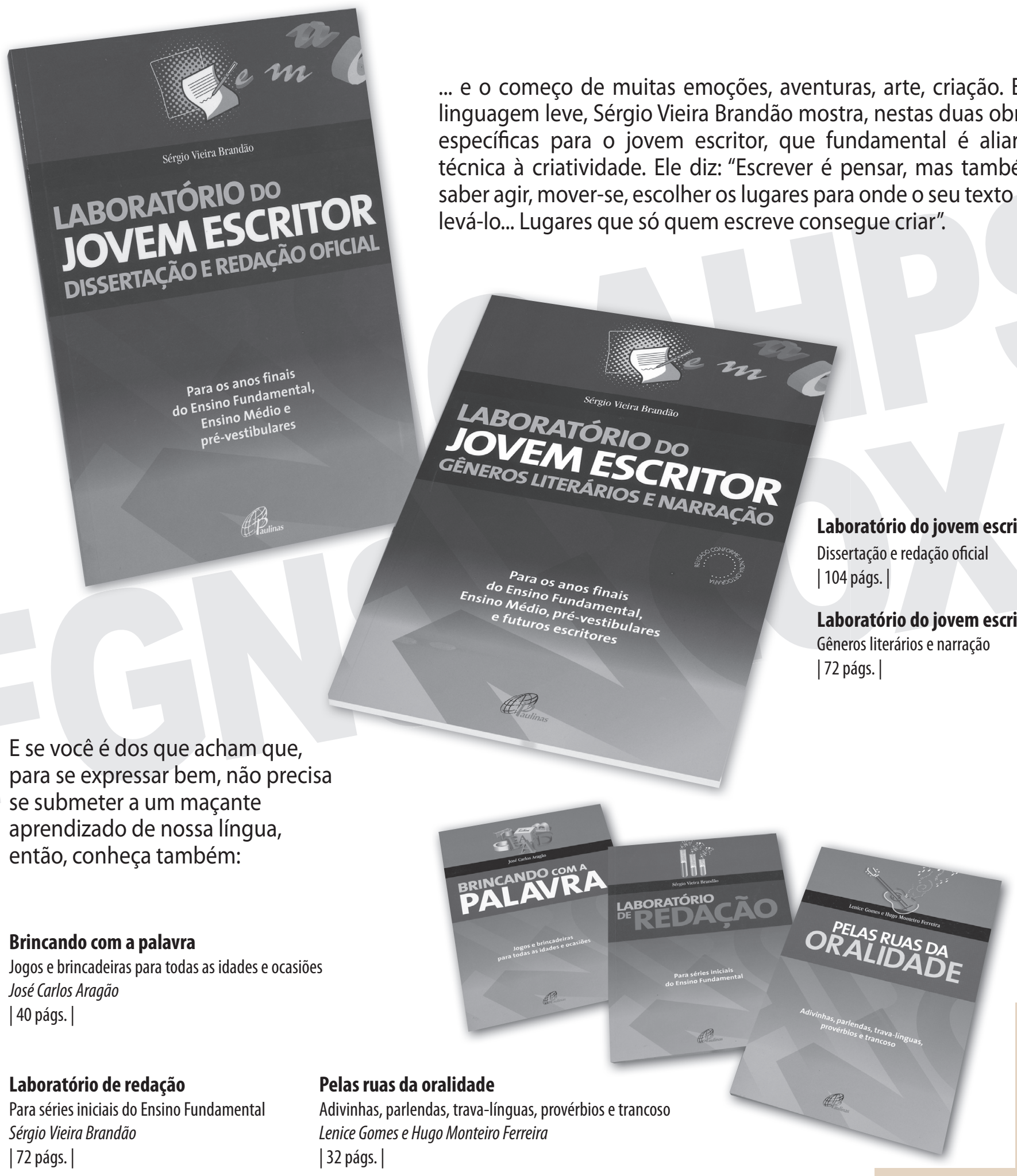

